\title{
Effects of murine recombinant interleukin 1 on intact homologous articular cartilage: a quantitative and autoradiographic study
}

\author{
WIM B VAN DEN BERG, ${ }^{1}$ FONS A J VAN DE LOO, ${ }^{1}$ WIL A ZWARTS, \\ AND IVAN G OTTERNESS ${ }^{2}$
}

From the ${ }^{1}$ Department of Rheumatology, University Hospital St Radboud, Nijmegen, The Netherlands; and the ${ }^{2}$ Department of Immunology, Pfizer Central Research, Groton CT

SUMMARY Murine recombinant interleukin 1 (IL1) was tested for its ability to affect intact murine articular cartilage. IL1 caused enhanced proteoglycan degradation and severe inhibition of chondrocyte synthetic function at a concentration of $3 \mathrm{U} / \mathrm{ml}(100 \mathrm{pg} / \mathrm{ml})$. Inhibition of proteoglycan synthesis appeared to be delayed in onset but occurred consistently after 24 hours. Pulse chase experiments made it clear that proteoglycan degradation and inhibition of proteoglycan synthesis are two distinct actions of IL1. No indications were obtained for selective degradation of either newly synthesised or processed proteoglycan. Moreover, chondrocyte synthetic activity appeared to be inhibited uniformly throughout the cartilage matrix, i.e., no evidence was found for selective suppression of cells in certain regions. IL1 uptake measurement in the cartilage, using $\left[{ }^{125} \mathrm{I}\right] \mathrm{IL} 1$, yielded a partition coefficient far below 1 , and autoradiography demonstrated a faint but even distribution within the cartilage matrix. The coordinated induction of enhanced breakdown of proteoglycan and inhibition of proteoglycan synthesis, with such low concentrations of IL1 reaching the chondrocytes, underlines the impressive destructive potential of IL1.

Key words: proteoglycan synthesis, cytokines, murine cartilage.

The term interleukin 1 (IL1) was originally introduced to describe a 17 kilodalton protein, secreted by activated cells of the macrophage/monocyte lineage, that augmented $\mathrm{T}$ cell proliferation to mitogens and antigens. ${ }^{1}$ This property was formerly known as lymphocyte activating factor (LAF) activity. It has now become evident that IL1 can affect multiple cell types and functions. For instance, IL1 may mediate fever, hepatic secretion of acute phase proteins, lymphocyte chemotaxis, fibroblast proliferation, and alterations in bone metabolism. ${ }^{2}$ Recent work using recombinant IL1 has confirmed that these several biological activities reside within one molecule. ${ }^{3}$ Earlier studies had suggested that IL1 is also involved in cartilage destruction in arthritic joints. Coculture of cartilage and synovial tissue resulted in severe chondrocyte mediated

Accepted for publication 11 March 1988.

Correspondence to Dr Wim van den Berg, Department of Rheumatology, University Hospital St Radboud, 6525 GA Nijmegen, The Netherlands. breakdown of cartilage proteoglycans. The substance responsible for this effect was termed catabolin. ${ }^{4}$ Similar effects were described for mononuclear cell factor, ${ }^{5}$ a product of stimulated human blood monocytes. When purified to homogeneity, catabolin and mononuclear cell factor were shown to have properties identical to those of IL1.67 It is now known that IL1 stimulates the release of metalloproteinases from chondrocytes. ${ }^{8-10}$ Interestingly, IL1-like activity has been identified in synovial fluid from patients with various types of joint disease..$^{11} 12$ Moreover, raised levels of cartilage derived proteases have been detected in cartilage specimens from patients with osteoarthritis. ${ }^{13} 14$

In the present study we describe the effects of murine recombinant IL 1 on chondrocyte metabolism, using anatomically intact homologous articular cartilage-the murine patella. Apart from an enhancing effect on proteoglycan breakdown, IL1 was shown to inhibit severely chondrocyte proteoglycan synthesis as measured by ${ }^{35} \mathrm{~S}$ incorporation. 
Autoradiography was performed to detect potential variability in IL1 sensitivity of chondrocytes in various regions. Finally, IL1 was radiolabelled to determine its partition in intact cartilage.

\section{Materials and methods}

\section{PREPARATION OF IL 1}

The published amino acid sequence of murine IL1 $\alpha$ was used to synthesise a cDNA fragment and this was expressed in Escherichia coli. The protein consisted of the carboxy terminal amino acids 115 to 270 of the IL1 propeptide. The molecule was purified from inclusion bodies and refolded into the biologically active form (G Daumy, to be published). Cyanogen bromide fragmentation was used for structural confirmation. Biological activity was verified in multiple assays (Otterness et al, in preparation). In the LAF assay the IL1 was found to give 1 unit activity consistently in the $10-40 \mathrm{pg} / \mathrm{ml}$ range. Screening for endotoxin activity (Limulus assay) was negative up to a concentration of $100 \mu \mathrm{g} / \mathrm{ml}$ IL1. The recombinant IL1 preparation was stored at $-20^{\circ} \mathrm{C}$ and showed consistent LAF activity over the period studied. Experiments were performed with two batches of IL1 prepared on different occasions. Effects on chondrocyte synthesis and cartilage breakdown were completely similar.

\section{LAF A C TIVITY}

Murine thymocytes from mice aged 6-7 weeks were cultured for four days in the presence of $1 \mu \mathrm{g} / \mathrm{ml}$ phytohaemagglutinin and various IL1 concentrations. Thymocytes were cultured at a concentration of $10^{7} / \mathrm{ml}$ in $200 \mu \mathrm{l}$ wells, and $\left[{ }^{3} \mathrm{H}\right]$ thymidine was added ( $37 \mathrm{kBq} /$ well) during the last day. One unit of LAF activity was defined as the IL1 concentration giving half the plateau of IL1 induced comitogenic thymocyte proliferation.

\section{CARTILAGE ASSAY}

Whole murine patellae were isolated from C57Bl mice leaving the patella embedded in a minimal amount of surrounding tissue and used to measure chondrocyte metabolism as described previously. ${ }^{15} 16$ In brief, patella specimens were cultured in RPMI-5\% fetal calf serum (Flow) under $5 \% \mathrm{CO}_{2}$ with or without IL1. Culture medium was refreshed every day. To determine chondrocyte proteoglycan synthesis the specimens were subsequently pulsed with $740 \mathrm{kBq}\left[{ }^{35} \mathrm{~S}\right]$ sulphate/ml for three hours. After washing, fixation in formalin $(10 \%)$, and decalcification in formic acid $(5 \%)$ the patella could easily be punched out of the adjacent tissue. The ${ }^{35} \mathrm{~S}$ content of each patella, which is a reliable measure of the
${ }^{35}$ S $]$ glycosaminoglycan content, ${ }^{17} 18$ was measured by liquid scintillation counting.

To measure the potential release of labelled proteoglycan into the medium $100 \mu \mathrm{l}$ aliquots of the $\overrightarrow{\overrightarrow{\mathrm{s}}}$ three hour $\left[{ }^{35} \mathrm{~S}\right]$ sulphate pulse medium of control and IL1 incubations were treated with $1 \%$ cetylpyridinium chloride. Non-labelled proteoglycan was $\frac{\overline{\bar{c}}}{\overline{7}}$ added as a carrier. After two hours at $37^{\circ} \mathrm{C}$ the $\underset{\Omega}{\square}$ precipitate was spun down at $10000 \mathrm{~g}$ for 30 minutes and the pellet was washed five times with $0.1 \%{ }^{\circ}$ ) cetylpyridinium chloride to remove adherent. $\left[{ }^{35}\right.$ S]sulphate. ${ }^{17}$ To correct for loss of $\left[{ }^{35}\right.$ S]proteo- $\overrightarrow{\vec{H}}$ glycan during this procedure the following standard ${ }_{\sigma}^{\omega}$ was included in the experiment: $\left[{ }^{35}\right.$ S $]$ proteoglycan $\frac{}{2}$ $(2000 \mathrm{cpm})$ from bovine cartilage supplemented? with $74 \mathrm{kBq}\left[{ }^{35} \mathrm{~S}\right]$ sulphate.

To determine IL1 mediated degradation the $\vec{\circ}$ patellae were prelabelled with $\left[{ }^{35}\right.$ S]sulphate $(6-24 \mathrm{~h})$ before IL1 exposure. After the culture period with IL1 the amount of ${ }^{35} \mathrm{~S}$ retained in the patellaro cartilage was measured and expressed as a percentage of the ${ }^{35} \mathrm{~S}$ content of control cartilage cultured $O$ without IL1.

To enable comparison of IL1 effects on newly足 synthesised and more extensively processed proteo- $\rightarrow$ glycans mice were injected intraperitoneally wisho $74 \mathrm{kBq} / \mathrm{g}$ body weight, and labelled patellae we isolated at days 1,2 , and 4 . The right patella wânis cultured in the presence of IL1 for 24 hours and tifes left patella was cultured without IL1.

The IL1 effect was always expressed in com parison with the value for the contralateral joint of the same animal. This approach minimises variation $\vec{B}$ due to interindividual difference in ${ }^{35} \mathrm{~S}$ incorpor 3 ation. ${ }^{15}$

\section{A U TORA DIOGRA P H Y}

Patella specimens were fixed and decalcified aş described above. After histological processing $6 \mu \mathrm{m}$ sections were prepared and mounted on gelatin coated slides. These were dipped in $\mathrm{K}_{\mathrm{s}}$ emulsion? (Ilford, Basildon, Essex, England) and exposed for three to five weeks. After this period the slides were developed and stained with haematoxylin and eosin $\frac{7}{0}$

\section{CARTILAGE HIST O LOGY}

Patella sections were stained with alcian blue for 24 hours. The dye was solved in an acetate buffer $(0.025 \mathrm{M}, \mathrm{pH} 5.4)$ at a concentration of $0.06 \%$, irw the presence of $0.3 \mathrm{M} \mathrm{MgCl}_{2}$. Decreased staining a the cartilage layer reflects loss of proteoglycano Similar results were obtained with Safranin O on Giemsa staining.

U P T A K E OF RA D I O L A B E L L ED I L 1
${ }^{125}$ I labelling of IL1 was performed by the method od 
Bolton-Hunter. Iodinated IL1 was separated from free ${ }^{125}$ I by Sephadex G-25 fractionation. The labelled preparation retained full biological activity, and the specific activity was approximately $37 \mathrm{kBq} / \mu \mathrm{g}$.

Patellae were incubated with $\left[{ }^{125} \mathrm{I}\right] \mathrm{IL} 1$ in phosphate buffered saline $(\mathrm{pH} \mathrm{7.4)}$ for various time periods at $37^{\circ} \mathrm{C}$. At the end of the incubation the specimens were rinsed once, blotted dry, and fixed in $10 \mathrm{ml}$ of $2.5 \%$ glutaraldehyde or formalin $(10 \%) /$ ethanol for 30 minutes. This was followed by decalcification in 5\% formic acid overnight. After a short fixation period the whole cartilage layer can easily be stripped from the underlying bone, ${ }^{17}$ and the amount of [ $\left.{ }^{125} \mathrm{I}\right] \mathrm{IL} 1$ present in the cartilage can be counted. The procedure of fixation of cartilage associated protein allows the release of free ${ }^{125} \mathrm{I}$ from the tissue: slight contamination of labelled protein solutions with free ${ }^{125}$ I would otherwise introduce significant errors owing to the relatively high uptake of free ${ }^{125}$ I compared with that of poorly penetrating proteins. The uptake of $\left[{ }^{125}\right.$ I] IL1 is expressed as a partition coefficient, which is the concentration in the cartilage divided by the concentration in the incubation medium. To obtain the partition volume of the patellar cartilage strip the cumulative wet and dry weights of 10 specimens were determined. The fluid phase of one patella strip was approximately $0.05 \mu \mathrm{l}$.

\section{Results}

\section{INHIBITION OF CHONDROCYTE}

PROTEOGLYCAN SYNTHESIS

Initially, whole patellae were incubated with various concentrations of murine recombinant IL1 for 48 hours, followed by a three hour pulse with $\left[{ }^{35} \mathrm{~S}\right]$ sulphate, to define the effective concentration range of IL1. IL1 caused a dose dependent inhibition of [ ${ }^{35}$ S]proteoglycan synthesis (Table 1). Concen-

Table 1 Dose dependent effect of ILI on ${ }^{35}$ S incorporation

\begin{tabular}{lll}
\hline $\begin{array}{l}\text { ILI } \\
\text { concentration* } \\
\text { (U/ml) }\end{array}$ & $\begin{array}{l}35 \text { S incorporationt } \\
\text { (cpm/patella) }\end{array}$ & Inhibition (\%) \\
\hline- & $357(33)$ & - \\
\hline $0 \cdot 03$ & $345(19)$ & 3 \\
$0 \cdot 1$ & $309(25)$ & 13 \\
$0 \cdot 3$ & $288(34)$ & 19 \\
$1 \cdot 0$ & $227(32)$ & 36 \\
$3 \cdot 0$ & $161(39)$ & 55 \\
$10 \cdot 0$ & $125(37)$ & 65 \\
$30 \cdot 0$ & $139(31)$ & 61 \\
\hline
\end{tabular}

Patellae were incubated for 48 hours.

*Values are $\mathrm{U} / \mathrm{ml}$, based on thymocyte proliferation.

+Values are the mean (SD) of six cartilage specimens. trations of IL1 of $0 \cdot 1 \mathrm{U} / \mathrm{ml}$ or below were essentially without effect. A plateau of maximal inhibition was reached at IL1 concentrations of $3 \mathrm{U} / \mathrm{ml}$ and higher. In multiple experiments inhibition ranged between 50 and $65 \%$ with an IL1 concentration of $3 \mathrm{U} / \mathrm{ml}$. Control incubations with recombinant IL2 (Amersham, England), tested in doses up to $30 \mathrm{U} / \mathrm{ml}$, failed to inhibit proteoglycan synthesis. To verify that we were really measuring IL1 mediated inhibition of synthesis and not enhanced breakdown of new proteoglycan synthesised at the same rate we checked the culture supernatant for labelled proteoglycan fragments. The amount released during the three hour ${ }^{35} \mathrm{~S}$ pulse period was less than $10 \%$ of the amount incorporated in the cartilage for both the control incubation and after 48 hours of IL1 exposure, and was therefore negligible.

Next, the effect on sulphate incorporation of time of exposure to IL1 was explored. After 24 hours IL1 exposure the suppression of chondrocyte synthesis $\left({ }^{35} \mathrm{~S}\right.$ incorporation) was variable $(5-20 \%)$, only rarely reaching statistical significance. Exposure of patellar cartilage to IL1 for 48 hours consistently resulted in extensive inhibition of proteoglycan synthesis (Table 2). This effect seems not to depend upon exposure of the cartilage to IL1 for $\mathbf{4 8}$ hours as incubation with IL1 for 24 hours followed by a

Table 2 Time dependence of ILI effect on synthesis

\begin{tabular}{llll}
\hline $\begin{array}{l}\text { Time } \\
(h)\end{array}$ & $\begin{array}{l}\text { ILl } \\
(\text { Ulml) }\end{array}$ & $\begin{array}{l}{ }^{35} \text { S incorporationt } \\
(\text { cpm/patella })\end{array}$ & Inhibition (\%) \\
\hline 24 & - & $737(163)$ & - \\
24 & 3 & $575(86)$ & 22 \\
48 & - & $626(95)$ & - \\
48 & 3 & $288(46)$ & $54^{*}$ \\
\hline
\end{tabular}

Patellae were exposed to IL1 for 24 or 48 hours, followed by a three hour pulse with $\left[{ }^{35} \mathrm{~S}\right]$ sulphate.

${ }^{*} \mathrm{p}<0.001$, compared with 24 hour value (Mann-Whitney).

+ Values are the mean (SD) of six cartilage specimens.

Table 3 Time lag in IL1 effect on synthesis

\begin{tabular}{lllll}
\hline $\begin{array}{l}\text { Incubation } \\
\text { with } \\
\text { IL1 }\end{array}$ & $\begin{array}{l}\text { Length } \\
\text { of } \\
\text { chase } \\
\text { (h) }\end{array}$ & $\begin{array}{l}35 \text { incorporation* } \\
\text { (cpm/patella) }\end{array}$ & $\begin{array}{l}\text { Inhibition } \\
\text { (\%) }\end{array}$ & p Valuet \\
\hline- & 48 & $540(67)$ & - & \\
\hline 3 & 45 & $452(35)$ & 16 & 0.001 \\
24 & 24 & $294(52)$ & 46 & NS \\
48 & - & $278(35)$ & 49 &
\end{tabular}

Patellae were incubated with IL1 $(3 \mathrm{U} / \mathrm{ml})$ for various periods, followed by a chase without IL1. At the end of the incubation patellae were pulsed with $\left[{ }^{35} \mathrm{~S}\right]$ sulphate for three hours.

${ }^{*}$ Values are the mean (SD) of six cartilage specimens.

tp Values compared with 48 hour IL1 exposure (Mann-Whitney). 
24 hour incubation with medium only led to the same total effect (Table 3). These data indicate that IL1 mediated suppression of chondrocyte proteoglycan synthesis is delayed in onset. We never observed a suppression exceeding $25 \%$ at 24 hours, even with IL1 concentrations up to $100 \mathrm{U} / \mathrm{ml}$. This indicates that slow diffusion of IL1 into the cartilage, reaching a sufficient level of IL1 near the chondrocyte in a retarded fashion, cannot be the reason for this time lag. We also looked for selective effects of IL1 on chondrocyte incorporation of $\left[{ }^{35} \mathrm{~S}\right]$ sulphate in different regions of the patella by performing autoradiography on semiserial patellar sections of cultured specimens. Uniform labelling of the cartilage layer was obtained after 48 hours' culture and three hours' $\left[{ }^{35} \mathrm{~S}\right]$ sulphate exposure (Fig. 1a). When the patellae were cultured in the presence of IL1, clear cut suppression of labelling intensity was observed (Fig. 1b). No evidence was obtained for a differential sensitivity to IL1 when the central or marginal regions, or the chondrocytes in superficial and deeper layers, were compared.

DEGRADATION OF $\left[{ }^{35}\right.$ S $]$ PROTEOGLYCANS Patellae prelabelled with $\left[{ }^{35} \mathrm{~S}\right]$ sulphate for six hours were cultured with or without IL1, and the amount of ${ }^{35} \mathrm{~S}$ retained in the patellar cartilage was determined. Significantly less ${ }^{35} \mathrm{~S}$ was retained in cartilage cultured in the presence of IL1 (Table 4), indicating that proteoglycan degradation was enhanced. The action of IL1 was not influenced by the presence of fetal calf serum in the medium (Table 4). When larger concentrations of IL1 (up to $100 \mathrm{U} / \mathrm{ml}$ ) were used, only slightly higher effects on breakdown were seen; not always reaching statistical significance compared with effects obtained with $3 \mathrm{U} / \mathrm{ml}$.

To investigate whether there might be a prefer- ential effect of IL1 on newly synthesised proteoglycan compared with older, more fully processed $\frac{D}{\omega}$. proteoglycan we carried out the following experi- $\because$ ment. Effects of IL1 were compared on cartilage $\bar{c}$ with variably processed proteoglycans, and foro optimal physiological processing of labelled proteo-흘 glycans labelling was performed in vivo. From $\overline{\bar{s}}$ earlier studies it was known that the amount of ${ }^{35}$ S]proteoglycan in patellar cartilage, after a single injection of $\left[{ }^{35} \mathrm{~S}\right]$ sulphate, reaches a plateaus between two and six hours and gradually decreases. thereafter. ${ }^{15}$ Therefore the effect of IL1 on patellar $\overrightarrow{-}$ cartilage isolated on days 1,2 , or 4 after $\left[{ }^{35} \mathrm{~S}\right]$ sulphate injection was determined (Table 5). Patellae taken at day 1 or 2 and cultured for 24 hours in the presence of IL1 both contained significantly less ${ }^{35} \mathrm{~S} . \mathrm{t}$ than those cultured in the absence of IL1. The enhancement of IL1 mediated breakdown was of the same order of magnitude for days 1 and 2. A similare result was found when the comparison was made between days 1 and 4 . We repeated this experiment

Table 4 ILI mediated breakdown

\begin{tabular}{|c|c|c|c|c|}
\hline${ }^{35} S$ Labelling* & ILI & Fetal & ${ }^{35} S$ content & \\
\hline (h) & $(U / m l)$ & $\begin{array}{l}\text { calf } \\
\text { serum } \\
(\%)\end{array}$ & cpm/patella & \% \\
\hline 6 & - & - & 1047 (179) & - \\
\hline 6 & 3 & - & 775 (151) & 74 \\
\hline 6 & - & 5 & $1060(244)$ & - \\
\hline 6 & 3 & 5 & 748 (110) & 71 \\
\hline 24 & - & 5 & 1897 (183) & - \\
\hline 24 & 3 & 5 & 1367 (189) & 72 \\
\hline
\end{tabular}

${ }^{*}$ Patellae were prelabelled with $\left[{ }^{35}\right.$ S $]$ sulphate for either six of 24 hours, followed by incubation for 24 hours with or without IL †Values are the mean (SD) of six cartilage specimens.

$\ddagger$ Compared with its proper control.
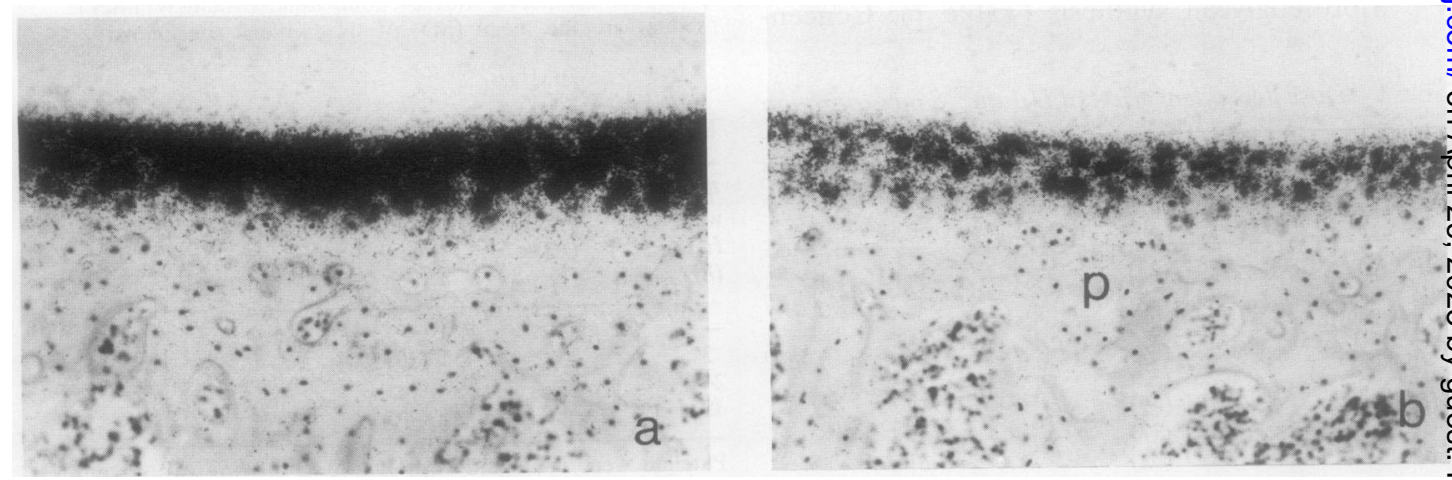

Fig. 1 Autoradiography of patellar cartilage after 48 hours' exposure to (a) medium or to (b) 3 U ILI/ml, followed by a three hour pulse with $\left[^{35}\right.$ S sulphate. Note the distinct labelling in (a) and the uniformly diminished labelling above all cells after ILI exposure in (b). $p=$ patella. 
Table 5 Comparison of the effect of ILI on newly labelled and more processed proteoglycan

\begin{tabular}{|c|c|c|c|c|}
\hline \multirow[t]{2}{*}{ Experiment* } & \multirow{2}{*}{$\begin{array}{l}\text { Time } \\
\text { (h) }\end{array}$} & \multirow{2}{*}{$\begin{array}{l}\text { ILl } \\
(U / m l)\end{array}$} & \multicolumn{2}{|l|}{${ }^{35} S$ content $\dagger$} \\
\hline & & & cpm/patella & $\% \ddagger$ \\
\hline A & 24 & - & $248(63)$ & - \\
\hline A & 24 & 3 & 185 & 75 \\
\hline A & 48 & - & $228(63)$ & - \\
\hline A & 48 & 3 & $180(42)$ & 79 \\
\hline B & 24 & - & $380(108)$ & - \\
\hline B & 24 & 3 & 275 (59) & 72 \\
\hline B & 96 & - & $302(76)$ & - \\
\hline B & 96 & 3 & $221(47)$ & 73 \\
\hline
\end{tabular}

Patellae were isolated and cultured for 24 hours with or without IL1, one patella without and the contralateral patella of the same animal with IL1.

${ }^{*}$ Mice were given an injection with $1.85(\operatorname{exp~A})$ or $2.78(\operatorname{exp~B)}$ MBq $\left[{ }^{35}\right.$ S $]$ sulphate.

$\dagger$ Values are the mean (SD) of cartilage specimens of seven mice. $\ddagger$ Compared with its proper control.

three times, with identical results. Finally, to verify that these results were not an artefact of radiolabelling, patellae were cultured for two days and then stained histologically. IL1 induced clear depletion of proteoglycan in the metabolically active superficial layer of the patella (Fig. 2).

IL 1 UPTAKE IN CARTILAGE

IL1 was radiolabelled to permit measurement of its effective concentration in cartilage. The labelled preparation retained full biological activity as tested in the cartilage and in the LAF assay. Patellae were incubated with [ ${ }^{125}$ I]IL1 for various time periods. The uptake reached equilibrium within 30 minutes, but the partition coefficient of the anionic IL1 (pI 5) remained far below 1 (Table 6 ).

A partition coefficient of 0.2 indicates that the local concentration is about five times less than the
IL1 concentration in the incubation medium. In contrast, the cationic protein amidated bovine serum albumin (aBSA; pI 8.5-9) ${ }^{19}{ }^{20}$ accumulated to a high extent in the cartilage and equilibrium was not reached even after four hours (Table 6).

Figure 3 depicts the autoradiography of IL1 and aBSA partition. In contrast with the high affinity of aBSA for the patellar cartilage (Fig. 3b), IL1 was predominantly taken up by the surrounding tissue (Fig. 3a). Higher magnification of the cartilage (Figs $3 \mathrm{c}$ and $\mathrm{d}$ ) showed that most of the IL1 radiolabel was present as a superficial lining layer, and that the quantitative measurement of the partition (Table 6) strongly overestimated the actual concentration within the matrix. If, after $\left[{ }^{125}\right.$ I] IL1 exposure, the patella specimens were washed with saline and then prepared for autoradiography, labelling was no longer detectable, either at the cartilage surface or within the matrix. The label present within the matrix showed a diffuse pattern over the whole cartilage area.

OTHER EFFECTS OF MURINE RECOMBINANT I L 1

Murine IL1 (pI 5) was examined in a number of

Table 6 ILI uptake in patellar cartilage

\begin{tabular}{llc}
\hline $\begin{array}{l}\text { Incubation time } \\
\text { (min) }\end{array}$ & \multicolumn{2}{l}{ Partition coefficient } \\
\cline { 2 - 3 } & ILI & aBSA† \\
\hline 10 & $0 \cdot 08$ & $3 \cdot 8$ \\
30 & $0 \cdot 15$ & ND $\dagger$ \\
60 & $0 \cdot 16$ & $10 \cdot 4$ \\
120 & $0 \cdot 14$ & $20 \cdot 2$ \\
240 & $0 \cdot 16$ & $33 \cdot 7$ \\
\hline
\end{tabular}

*The partition coefficient is defined as the concentration in the cartilage divided by the concentration in the surrounding fluid. $+\mathrm{aBSA}=$ amidated bovine serum albumin; $\mathrm{ND}=$ not done.

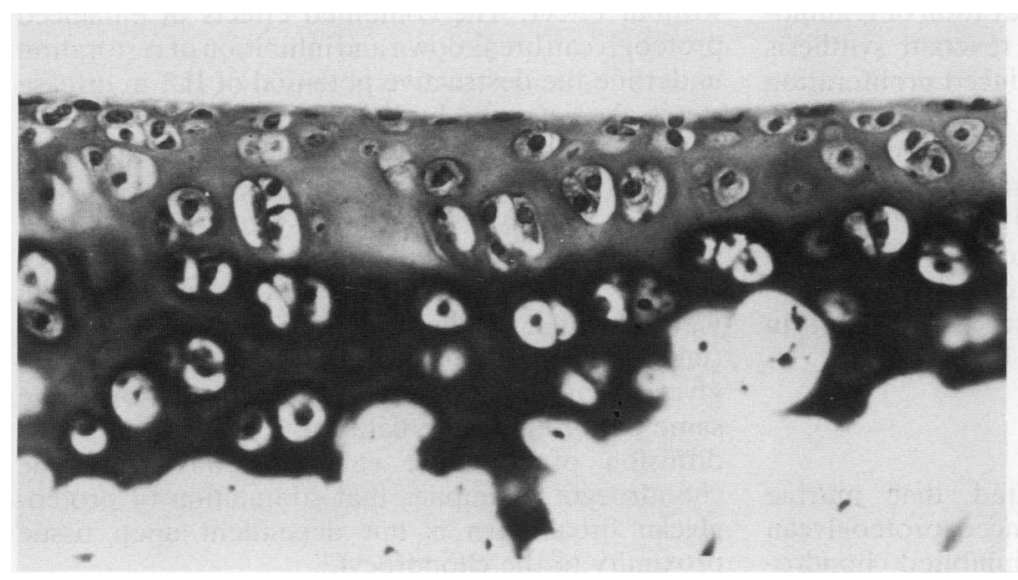

Fig. 2 Staining of the patellar cartilage after 48 hours' ILI exposure. Note the distinct loss of staining in the superficial layer, which is the metabolically active part of the cartilage (see Fig. 1). Halo formation around chondrocytes was not evident. 

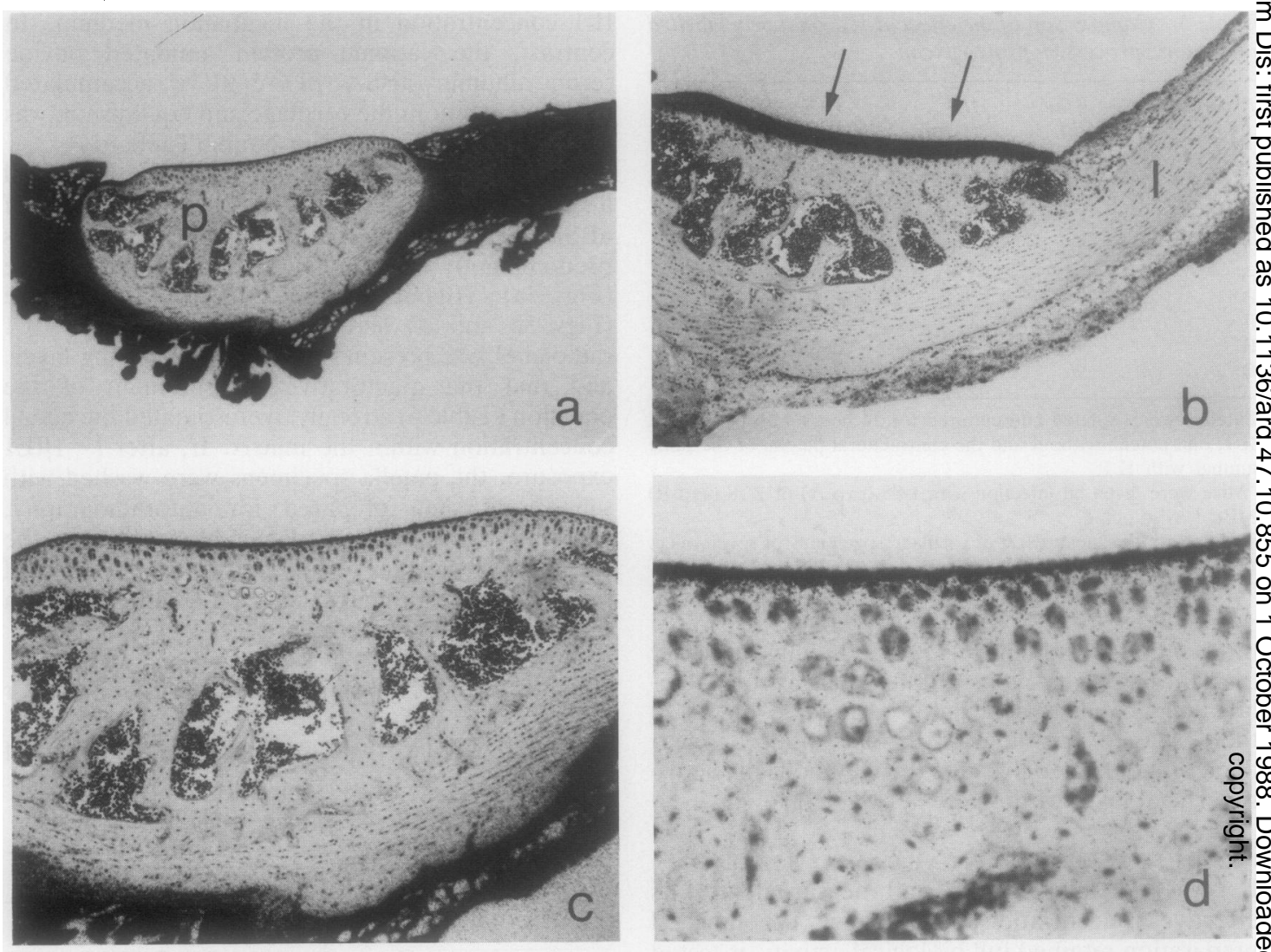

Fig. 3 Autoradiography, four hours after incubation of patellae with $(a, c, d) I^{125} I J I L 1$ or with (b) amidated bovine serum albumin $\left(l^{125} I J a B S A\right)$. (a) IL1 is predominantly present in the surrounding connective tissue and ligament structures.

(b) The cationic protein aBSA shows a high affinity for the patellar cartilage (arrows) and deeply penetrates the matrix.

(c) and (d) are at higher magnification than (a) to show that ILI is hardly present within the cartilage matrix. $p=$ patella; l=ligament.

other assays to compare its activity with that of native IL1. In vivo, in the mouse, we found it to induce fever, leucocytosis, i.e., elevation of granulocyte numbers, and acute phase reactant synthesis (serum amyloid $\mathrm{A}$ ). In vitro it induced proliferation of thymocytes in the LAF assay. In the latter assay the IL1 was found to give 1 unit of activity consistently in the $10-40 \mathrm{pg} / \mathrm{ml}$ range. Preliminary experiments further indicated that the IL1 preparation also caused cartilage breakdown and proteoglycan synthesis inhibition in vivo upon intraarticular injection in knee joints (manuscript in preparation).

\section{Discussion}

The present study demonstrated that murine recombinant IL1 not only enhanced proteoglycan breakdown but also extensively inhibited chondro- cyte proteoglycan synthesis in intact murine articulag cartilage. As a control the lymphokine IL2 was. without effect. The combined effects of enhanced proteoglycan breakdown and inhibition of restoration underline the destructive potential of IL1 in disease states characterised by IL1 overproduction.

IL1 mediated loss of proteoglycans from thes cartilage matrix does not seem to be a selective process. Newly synthesised proteoglycan and proteoglycan processed for four days are affected equally (Table 5). Earlier studies with catabolin yielded similar results. Release of newly synthesise $\delta^{5}$ (labelled) proteoglycans and unlabelled proteoglycans from catabolin treated cartilage followed the same pattern. ${ }^{21}$ These data are consistent with frees diffusion of catabolic enzymes away from the chondrocyte. It implies that stimulation of proteo glycan breakdown is not dependent upon tissue्d proximity to the chondrocyte. 
Upon stimulation with IL1 chondrocytes have been shown to release metalloproteinases capable of degrading both collagen and proteoglycan. ${ }^{82}$ Enzymes found in the medium of IL1 treated cartilage cultures are in the latent form and must be activated before they can be enzymatically assayed. ${ }^{22}$ This suggests that IL1 stimulated the release of latent metalloproteinases from chondrocytes and that a proportion of the enzyme is activated in situ in the matrix. Suggestive evidence for this mechanism stems from detailed analysis of cartilage proteoglycans after stimulation with IL1. ${ }^{23}$

In addition to proteoglycan degradation, IL1 induced extensive inhibition of chondrocyte proteoglycan synthesis. This inhibition appears to be retarded in onset. Effects were variable and not impressive at 24 hours but very significant at 48 hours. A similar delay in onset of action was described for catabolin. ${ }^{24}$ So far, the second messenger involved in the effect of IL1 on synthesis has not been elucidated. A recent report, however, clearly demonstrated the presence of specific IL1 receptors on chondrocytes. ${ }^{25}$ One could argue that the time lag in IL1 action on proteoglycan synthesis is compatible with the suggestion that IL1 may stimulate new synthesis of degradative enzymes and that the apparent inhibition seen at 48 hours is therefore due to a high level of proteoglycan degrading enzymes and more severe breakdown of new proteoglycans synthesised at a normal, i.e., unchanged, rate. No evidence has been found, however, for a faster, more extensive degradation of newly synthesised proteoglycan during the short ${ }^{35} \mathrm{~S}$ pulse after long term IL1 exposure. Tyler did not observe enhanced amounts of ${ }^{35} \mathrm{~S}$ labelled proteoglycan fragments in the culture medium of such IL1 treated and briefly ${ }^{35} \mathrm{~S}$ pulsed cartilage,${ }^{24}$ and in this study we obtained similar results. Moreover, our pulse chase experiment made it clear that 24 hour IL1 exposure, followed by a chase without IL1, resulted in the same extent of inhibition of synthesis (Table 3). This makes it highly unlikely that the inhibition of synthesis is due to enhanced breakdown as it is known that proteoglycan breakdown ceases within 24 hours of removal of IL1. ${ }^{21}$ Taken together, our data clearly indicate that IL1 has two effects on cartilage: firstly, enhanced degradation of proteoglycan; secondly, extensive inhibition of proteoglycan synthesis via an as yet unknown mechanism.

IL1 has to penetrate the cartilage before it is active. Uptake of a protein in hyaline cartilage depends on both its size and charge. Earlier studies from our group showed that proteins with an isoelectric point (pI) above 8.5 have a high affinity for the negatively charged cartilage and easily penetrate and accumulate in the dense matrix. ${ }^{19} 2026-28$ The data obtained for IL1 uptake in the present study indicate a partition coefficient of 0.2 , pointing to concentration of mediator inside the cartilage five times lower than in the surrounding fluid. This value is consistent with published results for cartilage distribution of other anionic proteins of similar molecular weight. ${ }^{29}$ Our autoradiography made it clear, however, that most of the radiolabel was located at the surface and that the actual IL1 concentration within the matrix was far less. These observations stress the need for autoradiographic control of radiolabel studies. The high amount of label at the surface is just a consequence of the technique used and does not reflect IL1 binding at that site. In uptake studies patella specimens are not washed, and surface binding of attached label does occur after fixation. When washed with saline before fixation, this label is not detectable anymore. Another relevant issue in uptake studies with labelled proteins is the potential change in behaviour due to labelling. We chose the mild iodination according to Bolton-Hunter and checked that the $\left[{ }^{125}\right.$ I]IL1 retained its full biological activity in our cartilage assay. Moreover, at most one ${ }^{125} \mathrm{I}$ molecule is introduced per IL1 molecule, making a behavioural change highly unlikely. Loss of activity in our cartilage assay was clear cut after choramine-T iodination of IL1 (data not shown). Earlier observations from our laboratory have indicated that penetration of anionic proteins increases when the cartilage matrix is depleted of proteoglycans. ${ }^{2026}$ This indicates that IL1 penetration and interaction with chondrocytes could be expected to increase in already damaged cartilage of an inflamed joint. Thus IL1 effects may be slightly higher in fibrous cartilage than in dense hyaline cartilage owing to penetration differences. Although the two forms of this mediator, IL1 $\alpha$ (pI 5) and IL1 $\beta$ (pI 7-8), differ considerably in isoelectric point, neither form has a pI above $8 \cdot 5$, and even IL1 $\beta$ would not be expected to accumulate in hyaline cartilage. ${ }^{28}$ Slight differences in potency between IL $1 \alpha$ and IL $1 \beta$, as noted in cartilage assays, ${ }^{7}$ are not likely to be caused by disparity in uptake, and probably relate more to differences in IL1 chondrocyte (receptor) interaction.

In experimental models of murine joint inflammation, such as zymosan or antigen induced arthritis, chondrocyte proteoglycan synthesis was already significantly suppressed at day $1 .^{16} 30$ From the present kinetic data it seems unlikely that IL1 is directly responsible for this early suppression. Diffusion of mediators of acute inflammation such as hydrogen peroxide ${ }^{31}$ or neutrophil enzymes such as elastase $e^{32}$ may play a part in this early phase. After the first day IL1 seems a likely candidate for 
the continuing suppression of proteoglycan synthesis. The suppression found in the models of experimental arthritis was of the same order of magnitude $(50-60 \%)$ as that obtained with IL1 in vitro. In vivo it was observed that there was a higher vulnerability of chondrocytes in certain regions of the articular cartilage. ${ }^{30}$ For instance, suppression of sulphate incorporation was more pronounced in chondrocytes of the central area of the patellar cartilage than in the margins. ${ }^{30}$ Evidence for an enhanced susceptibility of particular chondrocytes to IL1 effects was not observed in vitro in the present study. This could indicate that IL1 is not the mediator of the cartilage damage seen in these models. In vivo, however, load bearing may give rise to regional differences. Moreover, diffusion of proteolytic inhibitors or other protective factors from the margins, supplied in vivo, may lead to more pronounced suppression in the central area.

The importance of IL1 as a mediator of cartilage destruction in chronic destructive arthritis is yet to be determined. IL1 activity has been detected in synovial fluid of patients with rheumatoid arthritis. ${ }^{11} 12$ Inhibitors are also present in high amounts, however, and measurement of consistent IL1 activity depends upon separation of IL1 and its inhibitors by gel chromatography. ${ }^{34}$ Some inhibitors appear only able to block the IL1 comitogenic assay, ${ }^{36} 37$ but recently an inhibitor has been described which blocked fibroblast collagenase production, ${ }^{38}$ and this may be an important regulator of tissue destruction. IL1 must penetrate cartilage and escape from (local) inhibitors before it is active. The recent observation that IL1 could induce joint inflammation and cartilage degradation ${ }^{39-41}$ provides further evidence for its role as a key mediator. Experiments with selective (synthetic) inhibitors of IL1 effects, or IL1 synthesis and release, are needed to elucidate this issue fully.

The Molecular Genetics Group of Pfizer Central Research, Groton, is gratefully acknowleged for the preparation and purification of murine recombinant IL1. The authors wish to thank the staff of the animal laboratory, Marion Janssen, and Sonja van Oosterhout for secretarial assistance.

\section{References}

1 Mizel S B. Interleukin-1 and T cell activation. Immunol Rev 1982; 63: 52-72.

2 Dinarello C A. Interleukin-1. Rev Infect Dis 1984; 6: 51-95.

3 Dinarello C A, Cannon J G, Mier J W, et al. Multiple biological activities of human recombinant interleukin-1. J Clin Invest 1986; 77: 1734-9.

4 Dingle J T, Saklatvala J, Hembry R M, Tyler J A, Fell H B, Jubb R. A cartilage catabolic factor. Biochem J 1979; 184: 177-80.

5 Jasin H E, Dingle J T. Human mononuclear cell factors mediate cartilage matrix degradation through chondrocyte activation. J Clin Invest 1981; 68: 571-81.
6 Krakauer T, Oppenheim J, Jasin H E. Human interleukin mediates cartilage matrix degradation. Cell Immunol 1985; 9 양. 92-9.

7 Saklatvala J, Sarsfield S J, Townsend Y. Pig interleukinpurification of two immunologically different leucocyte proteiffR that cause cartilage resorption, lymphocyte activation añd fever. J Exp Med 1985; 162: 1208-22.

8 Deshmukh-Phadke K, Lawrence M, Nanda S. Synthesis collagenase and neutral proteases by articular chondrocyte stimulation by a macrophage derived factor. Biochem Bioph@ Res Commun 1978; 85: 490-6.

9 Schnyder J, Payne T, Dinarello C A. Human monocyte or recombinant interleukin 1s are specific for the secretion of (D) metalloproteinase from chondrocytes. J Immunol 1987; 138: 496-503.

10 Pasternak R D, Hubbs S J, Caccese R G, Marks R L, Cona雨 J M, Dipasquale G. Interleukin-1 stimulates the secretion of proteoglycan and collagen degrading proteases by rabbif articular chondrocytes. Clin Immunol Immunopathol 1986; $4 \mathrm{E}$ 351-67.

11 Wood D D, Ihrie E J, Dinarello C A, Cohen P L. Isolation $\vec{\oplus}$ an interleukin-1 like factor from human joint effusions. Arthrig Rheum 1983; 26: 975-83.

12 Bendtzen K, Peterson J, Halkjaer-Kristensen J, Ingema Hansen T. Interleukin-1 like activities in synovial fluids of patients with rheumatoid arthritis and traumatic synovitis. Rheumatol Int 1985; 5: 79-82.

13 Pelletier J P, Martel-Pelletier J, Howell D S, Ghandu偻 Mnaymneh L, Enis J E, Woessner J F. Collagenase ar collagenolytic activity in human osteoarthritic cartilage. Arthriț Rheum 1983; 26: 63-8.

14 Martel-Pelletier J, Pelletier J P, Cloutier J M, Howell \& Ghandur-Mnaymneh L, Woessner J F. Neutral protesses, capable of proteoglycan digesting activity in osteoarthritigaind normal human articular cartilage. Arthritis Rheum 1984:28 305-12.

15 van den Berg W B, Kruysen M W M, van de Putte L B A. Thīe mouse patella assay: an easy method of quantitating articul cartilage chondrocyte function in vivo and in vitro. Rheumat Int 1982; 1: 165-9.

16 Kruysen M W M, van den Berg W B, van de Putte L B $\overrightarrow{\widehat{F}}$ Significance of severity and duration of murine antigen induced arthritis for cartilage proteoglycan synthesis and chondrocytE death. Arthritis Rheum 1985; 28: 813-9.

17 de Vries B J, van den Berg W B, Vitters E, van de Putte L B A Quantitation of glycosaminoglycan metabolism in anatomica intact articular cartilage of the mouse patella: in vitro apt in vivo studies with ${ }^{35} \mathrm{~S}$-sulfate, ${ }^{3} \mathrm{H}$-glucosamine and ${ }^{3}{ }_{3}$ acetate. Rheumatol Int 1986; 6: 273-81.

18 de Vries B J, van den Berg W B, van de Putte L B A. Salicylagi induced depletion of endogenous inorganic sulfate. Potential role in the suppression of sulfated glycosaminoglycan synthesis in murine articular cartilage. Arthritis Rheum 1985; 28: 922-9

19 van den Berg W B, van de Putte L B A. Electrical charge of the antigen determines its localization in the mouse knee joir Deep penetration of cationic BSA in hyaline articular cartilage. Am J Pathol 1985; 121: 224-34.

20 van den Berg W B, van Lent P L E M, van de Putte L B $\AA$ Zwarts W A. Electrical charge of hyaline articular cartilage, fo role in the retention of anionic and cationic proteins. Cheo Immunol Immunopathol 1986; 39: 187-97.

21 Tyler J A. Chondrocyte mediated depletion of articuli cartilage proteoglycans in vitro. Biochem J 1985; 225: 493-5Q2

22 Campbell J K, Golds E E, Mort J S, Roughley P J. Hum articular cartilage secretes characteristic metal dependeax proteinases upon stimulation by mononuclear cell factor. Rheumatol 1986; 13: 20-7.

23 Campbell J K, Roughley P J, Mort J S. The action of hump articular cartilage metalloproteinase on proteoglycan and liff protein. Biochem J 1986; 237: 117-22. 
24 Tyler J A. Articular cartilage cultured with catabolin (pig interleukin-1) synthesizes a decreased number of normal proteoglycan molecules. Biochem J 1985; 227: 869-78.

25 Bird T A, Saklatvala J. Identification of a common class of high affinity receptors for both types of porcine interleukin-1 on connective tissue cells. Nature 1986; 324: 263-6.

26 van den Berg W B, van de Putte L B A. Zwarts W A, Joosten L A B. Electrical charge of the antigen determines intraarticular antigen handling and chronicity of arthritis in mice. J Clin Invest 1984; 74: 1850-9.

27 Schalkwijk J, van den Berg W B, van de Putte L B A, Joosten L A B, van den Bersselaar L. Cationization of catalase, peroxidase and superoxide dismutase. Effect of improved intraarticular retention on experimental arthritis in mice. J Clin Invest 1985; 76: 198-205.

28 van Lent P L E M, van den Berg W B, Schalkwijk J, van de Putte L B A, van den Bersselaar L. The impact of protein size and charge on its retention in articular cartilage. $J$ Rheumatol 1987; 14: 798-805.

29 Maroudas A. Physicochemical properties of articular cartilage. In: Freeman N A R, ed. Adult articular cartilage. 2nd ed. London: Pitman Medical, 1979.

30 van den Berg W B, Kruysen M W M, van de Putte L B A, van Beusekom H J, van der Sluis M, Zwarts W A. Antigen induced and zymosan induced arthritis in mice: studies on in vivo proteoglycan synthesis and chondrocyte death. BrJ Exp Pathol 1981; 62: 308-16.

31 Schalkwijk J, van den Berg W B, van de Putte L B A, Joosten L A B. An experimental model for hydrogen peroxide induced tissue damage. Arthritis Rheum 1986; 29: 532-8.

32 Schalkwijk J, van den Berg W B, van de Putte L B A, Joosten L A B. Elastase secreted by activated polymorphonuclear leucocytes causes chondrocyte damage and matrix degradation in intact articular cartilage: escape from inactivation by $\alpha_{1}$ proteinase inhibitor. Br J Exp Pathol 1987; 68: 81-8.
33 Bartholomew J, Lowther D A, Handley C J. Changes in proteoglycan biosynthesis following leucocyte elastase treatment of bovine articular cartilage in culture. Arthritis Rheum 1984; 27: 905-11.

34 Miossec P. Dinarello C A, Ziff M. Interleukin-1 lymphocyte chemotactic activity in rheumatoid arthritis synovial fluid. Arthritis Rheum 1986; 29: 461-70.

35 Lotz M, Carson D A, Vaughan J H. Characterization of interleukin-1 inhibitors in rhcumatoid synovial fluid. Arthritis Rheum 1986; 29: S38.

36 Rosenstreich D L, Korn J, Kabir S, Brown K M. Studies on a urine derived human interleukin-1 inhibitor. In: Kluger $\mathbf{M}$ J, Oppenheim J J, Powanda M C, eds. The physiologic, metabolic and immunologic actions of interleukin-1. New York: Alan R Liss, 1985: 419-28.

37 Muchmore A V, Decker J M. Uromodulin: a unique 85 kilodalton immunosuppressive glycoprotein isolated from urine of pregnant women. Science 1985; 229: 479-81.

38 Balavoine J F, de Rochemonteix B, Williamson $\mathrm{K}$, Seckinger $\mathrm{P}$, Cruchaud A, Dayer J M. Prostaglandin $E_{2}$ and collagenase production by fibroblasts and synovial cells is regulated by urine-derived human interleukin-1 and inhibitors(s). $J$ Clin Invest 1986; 78: 1120-4.

39 Pettipher E R, Higgs G A. Henderson B. Interleukin-1 induces leucocyte infiltration and cartilage proteoglycan degradation in the synovial joint. Proc Natl Acad Sci USA 1986; 83: 8749-53.

40 Dingle J T, Page Thomas D P, King B, Bard D R. In vivo studies of articular tissue damage mediated by catabolin/ interleukin 1. Ann Rheum Dis 1987; 46: 527-33.

41 Dingle J T, Page Thomas D P, Hazleman B. The role of cytokines in arthritic diseases: in vitro and in vivo measurements of cartilage degradation. Int J Tissue React 1987; IX: $349-54$. 